\title{
APRENDIZAGEM COOPERATIVA NO ENSINO CONTÁBIL
}

\author{
COOPERATIVE LEARNING IN ACCOUNTING EDUCATION
}

\author{
Victória Benevides ${ }^{1}$ \\ Faculdade de Ciências Aplicadas e Sociais \\ de Petrolina (FACAPE) \\ victoriapassos_vivi@hotmail.com
}

\author{
Raimundo Nonato Lima Filho \\ Universidade de Pernambuco (UPE) e \\ Faculdade de Ciências Aplicadas e Sociais \\ de Petrolina (FACAPE) \\ rnlfilho@gmail.com
}

\begin{abstract}
RESUMO
As atividades praticadas pelos estudantes no ensino tradicional usualmente não permitem vivenciar experiências de trabalho de cooperação, de partilha de responsabilidades e não possibilita também a construção de relações positivas entre os integrantes dos grupos, enquanto que a aprendizagem cooperativa tem sido descrita pela literatura especializada como uma forma eficaz de praticar de modo concreto a diferenciação em sala de aula. Esta pesquisa teve como objetivo verificar as contribuições advindas de um método ativo de ensino. Neste estudo, foi realizado um experimento, adotando a Taxonomia de Bloom, no qual o grupo que obteve o ensino de forma ativa teve um desempenho superior ao grupo cujo ensino foi de forma tradicional. Além disso, também foram verificadas relações com a nota, com a idade, sexo e tipo de escola estudada durante o ensino médio, para assim identificar a influência desses fatores na nota final. Com base nos resultados obtidos, constatou-se que esse estudo contribuiu de forma positiva para o ensino/aprendizado, pois com ela há um estímulo cognitivo desencadeando a percepção do aluno sobre o conteúdo ministrado, e assim tornando o aprendizado mais estimulante.
\end{abstract}

Palavras-chave: Experimento. Técnica de Cloze. Aprendizagem Cooperativa.

\section{ABSTRACT}

The activities practiced by the students in the traditional teaching usually don't allow the experience of cooperative work, sharing of responsibilities and also the construction of positive relationships between group members, while cooperative learning has been described by specialized literature as an effective way to practice. Concretely the differentiation in the classroom. This research aimed to verify the contributions coming from an active teaching method. In this study, an experiment was performed, adopting Bloom's Taxonomy, in which the

\footnotetext{
${ }^{1}$ Avenida Veremundo Soares, s/n - Zona Rural, Salgueiro - PE, 56000-000
} 
group that obtained the active teaching had a better performance than the group whose teaching was traditionally. Besides, it was also verified relations with the grade, such as age, sex and type of school studied during high school, in order to identify the influence of these factors on the final grade. Based on the results obtained, it was found that this study contributed positively to teaching / learning, because with it there is a cognitive stimulus triggering the student's perception of the content taught, thus making learning more stimulating.

Keywords: Experiment. Cloze Technique. Cooperative Learning.

\section{INTRODUÇÃO}

O aprendizado e os conhecimentos adquiridos durante uma graduação tem papel fundamental e refletem na vida profissional e no comportamento do indivíduo ao longo da sua vida. $\mathrm{O}$ estudo sobre a aprendizagem cooperativa possui relevância, pois indicam a qualidade desse estilo de aprendizagem e de ensino, a capacidade do aprendiz em perceber e processar informações, e pode trazer reflexão e esclarecimento sobre os rendimentos dos discentes.

O estilo de aprendizagem está firmemente relacionado ao desenvolvimento de algumas características próprias do indivíduo, como sua personalidade, a percepção e análise das informações recebidas, preferências, contexto do ensino e características pessoais de aprendizado, aonde suas atuações são interdependentes do fator aprendizado (DALFOVO et al., 2017).

A capacidade técnica, não é mais suficiente para o ambiente de trabalho na atualidade como uma das habilidades que era desejada até o final do século XX (PEREIRA; SILVA, 2018). Rebele (1985) desenvolveu uma pesquisa que relatou que a comunicação oral era uma das mais importantes características nos indivíduos.

Em um estudo de análise das habilidades desejadas dos contadores, realizado pela International Federation of Accounting (IFAC) (2012), foi destacado as habilidades específicas e separadas em: intelectuais, técnicas e funcionais, pessoais, interpessoais e de comunicação e organizacionais e de gerenciamento de negócios. Contudo, segundo Awayiga, Onumah e Tsamenyi (2010), a educação contábil ainda não desenvolveu um modelo de aprendizagem capaz de formar profissionais com as tais habilidades requisitadas.

Silva et al. (2012) versam sobre a importância de se ter a percepção que mesmo que um aluno tenha aprendido melhor de uma maneira específica, ele deve ser exposto a várias outras experiências de aprendizagem para que o aprendizado se torne mais versátil. Quando os estilos de aprendizagem dos alunos são identificados, é possível definir um contexto apropriado da aprendizagem.

A taxonomia dos métodos educacionais é um método de organização baseado numa escala tendo objetivos didáticos. A taxonomia original de Bloom (taxonomia cognitiva) apresenta definições para as seis principais categorias do domínio cognitivo: conhecimento, compreensão, aplicação, análise, síntese e avaliação. Estas categorias estão ordenadas da mais simples para a mais complexa (LIMA FILHO, JESUS, 2013). Sendo assim a taxonomia é uma hierarquia cumulativa, onde uma categoria mais simples é pré-requisito para a próxima categoria mais complexa (KRATHWOHL, 2002).

A utilização deste estudo poderá ajudar na compreensão sobre a adaptação dos educandos do curso de graduação quanto à forma cooperativa de estudo, a partir de uma adaptação de Pereira e Silva (2018), percebendo assim que o ensino através da abordagem cooperativa poderá trazer benefícios ao desempenho e a comunicação.

Tendo a comunicação como característica de grande importância no meio acadêmico e principalmente no mercado de trabalho, a questão problema deste estudo é: "A aprendizagem 
através do método cooperativo favorece o desempenho acadêmico e a comunicação entre os discentes do curso de Ciências Contábeis?".

Este estudo tem como objetivo verificar as contribuições trazidas pela aprendizagem cooperativa, no desempenho acadêmico e na comunicação entre os discentes de Ciências Contábeis. Com isso, esta pesquisa se justifica com a importância da utilização de novas metodologias de ensino e do desempenho da habilidade da comunicação, não só para desenvolvimento acadêmico, mas também para desenvolvimento profissional, para que atenda todas as exigências atualmente impostas pelo mercado para o profissional contábil.

Tendo em vista o cenário mundial globalizado e todas as suas exigências, é necessário que o profissional cada vez mais, busque aperfeiçoar e/ou adquirir competências e habilidades que não lhe foram passadas ou foram transmitidas superficialmente, no meio educacional tradicional. A integração da Tecnologia da Informação e Comunicação (TIC) é uma técnica relevante na aquisição de novos conhecimentos, pois promove a possibilidade de controle, seja pelo tipo de relações cooperativas estabelecidas entre professores, alunos e colegas, ou por outros meios.

Este estudo está organizado em cinco capítulos. Este, a introdução, apresenta o contexto, o problema e objetivo da pesquisa, além de sua justificativa. O segundo é a plataforma teórica que dá sustentação para a parte empírica da investigação. O terceiro capítulo descreve as decisões metodológicas que conduzem a análise aplicada dos dados que estão no quarto capítulo. Por fim, o último capítulo, condensa todo o texto, concluindo com os principais achados, além de apresentar as limitações do estudo e sugestões para pesquisas futuras.

\section{REFERENCIAL TEÓRICO}

\subsection{ESTILOS DE APRENDIZAGEM}

Os estilos de aprendizagem são reconhecidos por comportamentos cognitivos, afetivos e psicológicos, e apontam como os aprendizes compreendem, interagem e respondem ao ambiente de aprendizado. A melhoria do processo de ensino-aprendizagem exige o conhecimento dos fatores que influenciam desempenho dos alunos (CONCEIÇÃO et al., 2013).

Cordeiro e Silva (2012) discutem que o conhecimento dos variados estilos de aprendizagem tende a resultar na otimização da qualidade do processo de ensino-aprendizagem, pois com isso tem-se a possibilidade de se desenvolver métodos e técnicas de ensino de acordo com as características pessoais dos acadêmicos.

Cada indivíduo possui sua forma de aprender única e pessoal, ou seja, o estilo de aprendizagem não é o que a pessoa aprende, mas sim o modo como ela se porta durante o aprendizado (REIS et al., 2012). Esses autores ainda afirmam que o estilo de aprendizagem compreende as formas, os métodos, o processo, como também o caminho que um indivíduo usa para obter conhecimento.

Existem inúmeras classificações de estilos de aprendizagem, em geral, com destaque em características do ser humano. Características essas que são apreendidas culturalmente e desenvolvidas a partir das experiências vividas (FILATRO, 2015).

Os estilos de aprendizagem do modelo VARK foram desenvolvidos e apresentados por Fleming e Mills (1992), eles discorrem sobre os métodos mais usuais que são aplicados no ensino, e assim são verificados como métodos de aprendizagem. Esse modelo consiste em: estilo Visual, estilo Auditivo, Leitura e Escrita, Sinestésico e Multimodal. 
Quadro 1 - Modelo VARK de Fleming e Mills adaptado.

\begin{tabular}{|c|l|}
\hline ESTILO & \multicolumn{1}{c|}{ DESCRIÇÃO } \\
\hline Visual (V) & $\begin{array}{l}\text { Nesse estilo o aprendizado se dá melhor por meio de esquemas, figuras, gráficos e } \\
\text { outros recursos visuais. }\end{array}$ \\
\hline Estilo Auditivo (A) & $\begin{array}{l}\text { O processo de aprendizado prefere ser na presença do professor, onde o aluno escuta } \\
\text { as informações e explicações que são transmitidas por meio da fala. Ao passo que esse } \\
\text { estilo se aprende melhor por sons, pode facilmente se distrair e desviar a atenção com } \\
\text { outros sons que envolvem o ambiente de sala de aula. Aulas palestradas pode ser a } \\
\text { preferência por esse tipo de aluno. }\end{array}$ \\
\hline Leitura e Escrita \\
(R) & $\begin{array}{l}\text { Esse estilo condiz sobre duas palavras, respectivamente, Leitura e Escrita. Alunos que } \\
\text { possuem esse perfil preferem estudar isoladamente, presos a textos de leituras. Outra } \\
\text { característica deste grupo é que possuem facilidades com a escrita, esse aluno } \\
\text { desenvolve melhor trabalhos que necessitem a busca por livros, se dão melhor com } \\
\text { conceitos teóricos e preferem deixar formalizados seus conhecimentos no papel, } \\
\text { tendem a ser mais teóricos. }\end{array}$ \\
\hline Sinestésico (K) & $\begin{array}{l}\text { Esse estilo prefere trabalhos em grupo, o aluno possui como principal característica a } \\
\text { aprendizagem por meio de experiências. Além disso, ao contrário do estilo Leitura e } \\
\text { Escrita, possui pré-disposição pela colaboração entre os agentes envolvidos no } \\
\text { processo de aprendizagem. Aulas práticas são preferidas por esse estilo. }\end{array}$ \\
\hline Multimodal (M) & $\begin{array}{l}\text { Considerado híbrido e em um mesmo nível possui dois ou mais estilos do Modelo } \\
\text { VARK. Esse estilo consegue se adequar melhor a diversas situações já que sua } \\
\text { adaptabilidade para um método de ensino é fluída. }\end{array}$ \\
\hline
\end{tabular}

Fonte: Fleming e Mills, 1992.

A contribuição do aluno no processo de ensino-aprendizagem é tão importante quanto o papel do educador, independente da forma que o conhecimento está sendo abordado, pois, o papel do professor é mediar o ensino e não somente transmiti-lo, então quando o docente consegue identificar o estilo de aprendizagem característico do discente, o entendimento do conteúdo acontece de forma mais natural, mas, isto ocorre porque o conteúdo está sendo apresentado de uma forma mais atrativa ao aluno, de forma que ele compreenda melhor (DALFOVO et al., 2017).

O comprometimento do aluno no processo de aprendizagem é tão importante quanto a dedicação do professor na aplicação do conhecimento, pois quanto mais alinhados estiverem os objetivos de ambas as partes, melhor será resultado obtido. Quando o educador possui um relacionamento próximo com o aluno é possível que ele identifique o grau de compreensão sobre as questões aplicadas, para que possa traçar metas mais específicas, e assim o indivíduo terá a capacidade para progredir no que foi proposto (MIRANDA; MIRANDA; COSTA, 2011).

\subsection{APRENDIZAGEM COOPERATIVA}

É habitual nas práticas didáticas o professor ser a peça central na transmissão dos conhecimentos, ao passo que os alunos são os receptores das informações. Dentre os vários métodos de ensino existentes, este é designado como ensino tradicional, e contempla um ensino individualista e em muitas ocasiões competitivo entre os alunos, dificultando a existência de momentos de partilha de conhecimentos, estímulos e desenvolvimento de competências sociais como, a colaboração e a ajuda (CUNHA; UVA, 2016).

As atividades praticadas pelos estudantes no ensino tradicional não permitem vivenciar experiências de trabalho de cooperação, de partilha de responsabilidades e não possibilitam também a construção de relações positivas entre os integrantes do grupo (LOPES; SILVA, 2009).

As interações sociais têm assumido uma importância maior no desenvolvimento cognitivo, a aprendizagem cooperativa tem sido descrita como uma forma eficaz de praticar de modo concreto a diferenciação em sala (CUNHA; UVA, 2016). 
A aprendizagem cooperativa é uma ferramenta de ensino e aprendizagem em grupos de pequeno tamanho, em que os alunos apresentam níveis de aprendizagem e de capacidade distintos, cada membro deste grupo apresenta uma função e todos são responsáveis por aprender o que está sendo ensinado (LOPES; SILVA, 2009).

A aprendizagem cooperativa é uma estratégia de aprendizagem que, quando aplicada de forma sistemática e assertiva, leva a melhores resultados de aprendizagem, independente, do nível de ensino ou das características dos alunos. É a metodologia mais benéfica para os alunos, promovendo atitudes mais positivas em relação às novas aprendizagens, se comparada a uma aprendizagem mais individualista (BESSA; FONTAINE, 2002).

Pereira e Silva (2018) analisaram como aprendizagem colaborativa pode contribuir para o desempenho acadêmico e para a habilidade de comunicação dos acadêmicos de Ciências Contábeis. A partir de uma amostra de 34 alunos de Contabilidade Fiscal, concluindo que a aprendizagem cooperativa contribuiu para a melhoria da habilidade de comunicação escrita, mas não apresentou diferença significativa na categoria aplicação.

\subsection{DESEMPENHO ACADÊMICO}

O desempenho acadêmico pode ser estabelecido como o retorno alcançado pelo desempenho das atividades acadêmicas, representando assim o nível de habilidade alcançado pelo estudante (MUNHOZ, 2004).

São várias as formas utilizadas nas instituições de ensino superior para medir e avaliar o desempenho dos discentes, algumas delas são as notas nas avaliações e médias gerais, além disso, existem também avaliações externas como o Exame Nacional de Desempenho dos Estudantes (ENADE) (BORGES et al., 2017).

O desempenho acadêmico pode ser influenciado por variáveis relacionadas ao corpo docente, discente e à instituição de ensino. É importante salientar que as variáveis relacionadas aos discentes são apontadas como as que operam maior influência no desempenho dos mesmos (CORBUCCI, 2007).

Para o sucesso do processo de ensino-aprendizagem, a avaliação deve ser dividida em três funções: a diagnóstica, a formativa e a somativa (SANTOS, 2005). A avaliação diagnóstica é aquela que verifica o conhecimento inicial do aluno de acordo com determinado conteúdo. Ela é realizada previamente, a fim de verificar as limitações, problemas e defeitos existentes e suas possíveis causas. A avaliação formativa está associada aos esforços despendidos para acrescentar ao aprendizado, e verificar a aceitabilidade do ensino, ela ocorre ao longo do processo de ensino-aprendizagem. A avaliação somativa acontece por fim, com o intuito de classificar os alunos de acordo com o seu aproveitamento e a sucessão de categoria (SHAFTEL; SHAFTEL, 2007; SANTOS, 2005).

\subsection{MÉTODOS DE ENSINO}

É notório que os métodos de ensino têm se aprimorado cada vez mais, com o objetivo de tornar o aprendizado para o aluno o mais proveitoso possível, novas técnicas que são melhor assimiladas pelos alunos vem surgindo, tomando lugar das técnicas padronizadas mais antigas que pouco despertava o interesse do aprendiz em buscar mais conhecimento.

O método mais tradicional consiste na técnica expositiva, na qual o professor é o provedor de toda informação e conhecimento, e tem função de passar aos seus alunos esses saberes, bem como aconselhar e corrigir. $O$ professor como peça central na obtenção do conhecimento também exerce a função de organizar e ordenar o conteúdo abordado para um melhor aproveitamento do aprendiz (PEREIRA; SILVA, 2018). 
As novas técnicas de ensino partem do princípio que o professor é um facilitador no desenvolvimento espontâneo do indivíduo em busca do conhecimento, para que ele desenvolva as próprias buscas e se adapte a melhor maneira de aprender, testando novos caminhos para chegar ao objetivo, sem ficar preso apenas ao que é passado em sala de aula. O professor é um estimulador dos alunos, para que estes desenvolvam suas habilidades e características ao longo do processo de aprendizagem (PEREIRA; SILVA, 2018).

Sendo assim, o professor não precisa e não deve ser aquele que tem uma técnica definida apenas com intuito de ensinar o conteúdo que lhe é cabível, mas sim assumir um papel de facilitador e estimulador, que intermedeia o aluno e a informação, com isso as suas técnicas metodológicas devem estar em constante aperfeiçoamento, para atender as necessidades que se manifestam (VEIGA, 2006).

Perspectivas modernas trazidas pelos avanços tecnológicos facilitaram o acesso à informação, e favoreceram o surgimento de novas necessidades. Assim, as metodologias e os métodos de ensino devem acompanhar essa evolução, e as estratégias devem ser sempre aprimoradas (VEIGA, 2006).

\subsection{TAXONOMINA COGNITIVA}

Segundo Galhardi e Azevedo (2013), Benjamin S. Bloom em conjunto com outros educadores consideraram a ideia de classificar metas e objetivos educacionais com o intuito de desenvolver um sistema de classificação para três domínios: o cognitivo, o afetivo e o psicomotor; e então criaram, no domínio cognitivo, a Taxonomia de Bloom.

Krathwohl (2002) explica que a principal ideia da taxonomia é que o que os educadores esperam que os alunos aprendam possa ser ordenado numa hierarquia, do nível de menor complexidade para o de maior. Para isso os níveis são sucessivos, de modo que um nível deve ser dominado antes que o próximo nível seja alcançado.

A dimensão dos Processos Cognitivos abrange cinco categorias da taxonomia original, com mudanças em seus nomes, em alguns casos, apenas para suas formas verbais. A categoria Conhecimento tornou-se Lembrar; Compreensão tornou-se Entender; Síntese tornou-se Criar (e foi promovida para a categoria mais alta da hierarquia); Aplicação, Análise e Avaliação tornaram-se respectivamente Aplicar, Analisar e Avaliar (KRATHWOHL, 2002; PINHEIRO et al, 2013).

Os instrumentos de aprendizagem puderam ser trabalhados de forma mais integrada e estruturada, inclusive considerando os avanços tecnológicos que podiam prover novas e diferentes ferramentas para facilitar o processo de ensino e aprendizagem, pois a taxonomia trouxe a possibilidade de padronização da linguagem no meio acadêmico e, com isso, também novas discussões ao redor dos assuntos relacionados à definição de objetivos instrucionais (FERRAZ; BELHOT, 2010).

\section{METODOLOGIA}

Este trabalho adota o tipo de pesquisa exploratória, em que a preocupação primordial é identificar os fatores que determinam ou contribuem para a ocorrência dos fenômenos. Esse tipo de pesquisa aprofunda o conhecimento da realidade, pois explica a razão das coisas. Devido a isso, é considerado o tipo mais complexo e delicado de se realizar (GIL, 2008).

A pesquisa se caracteriza em experimental, segundo Prodanov e Freitas (2013), caracteriza-se por manipular as variáveis relacionadas com o objeto de estudo. Nesse tipo de pesquisa, a manipulação das variáveis proporciona o estudo da relação entre as causas e os efeitos de determinado fenômeno. Através da criação de situações de controle, procura-se evitar a interferência de variáveis intervenientes. 
O experimento contou com um grupo controle, composto por 22 alunos, que executou o método tradicional de ensino (aula expositiva), e um grupo experimental, que executou o método cooperativo, composto por 10 alunos.

O nível de conhecimento foi baseado na Taxonomia de Bloom, tendo em vista a importância desta para o aprendizado, utilizando a técnica de aplicação, durante o experimento, onde a aplicação é a operacionalização do método, no caso, cooperativo (PEREIRA; SILVA, 2018).

Para avaliação da aplicação do método cooperativo, foram aplicadas avaliações, no final do experimento, utilizando a técnica Cloze, introduzida por Taylor em 1953, na sua elaboração, que consiste na utilização de frases ou textos, faltando algumas palavras, e estas devem ser preenchidas pelos alunos.

Essa técnica visa medir o aprendizado, através da contagem percentual de palavras que cada leitor preenche assertivamente num espaço em branco, ou seja, algumas palavras dos textos são excluídas de algum trecho e, se considera existir a compreensibilidade se o leitor conseguir colocar as palavras corretas nos espaços em branco (BORMUTH, 1962).

A análise dos dados se dará de forma descritiva que, de acordo com Cervo, Bervian e Silva (2007) na pesquisa descritiva se observa, registra, analisa e relaciona situações ou acontecimentos, porém sem que estas variáveis sejam manipuladas. Este tipo de pesquisa tem como objetivo principal a descrição das características de determinada população ou fenômeno ou, o estabelecimento de relações entre variáveis (GIL, 2008).

A amostra do estudo foi formada por conveniência e acessibilidade possuindo 32 alunos da disciplina Contabilidade Básica dos turnos vespertino e noturno, do segundo período do curso de Ciências Contábeis da Faculdade de Ciências Aplicadas e Sociais de Petrolina (FACAPE). Os grupos foram definidos de acordo com o turno, no turno vespertino foi aplicado o método Cooperativo e o turno noturno foi o grupo controle, ou seja, utilizou o método tradicional de ensino.

O grupo experimental que trabalhou com o método cooperativo, foi dividido em três grupos, um grupo com quatro integrantes e dois grupos com três integrantes. Devido à quantidade de alunos, não foi possível dividi-los em grupos com quantidades iguais.

Todos os grupos receberam um material (APÊNDICE A) sobre o conteúdo Apuração do Resultado Exercício (ARE), e assim estudaram em grupo durante o tempo estipulado, logo após esse momento, houve uma discussão entre os grupos sobre o assunto. Concluída essa etapa, foi desenvolvida uma atividade sobre o conteúdo em que cada grupo resolveria e depois apresentava as respostas para a turma como um todo, depois de finalizado a aplicação do método cooperativo de aprendizado, foi aplicado o instrumento de avaliação do aprendizado (APÊNDICE B), que continham frases para ser completadas.

O grupo controle teve a aula expositiva tradicional, aplicada pelo professor da disciplina e após finalizada foi aplicado o mesmo instrumento de avaliação do aprendizado (APÊNDICE B). A nota atribuída teve como base o número de acerto dos quesitos presentes no instrumento, ou seja, o preenchimento correto das lacunas.

A análise dos dados foi realizada após os testes de média, variância e correlação. Para a correlação utilizou-se os dados sexo, idade e tipo de escola estudado durante o ensino médio.

A avaliação da comunicação se deu por observação, no momento da aplicação do método de ensino cooperativo, e verificou-se que houve uma interação significativa entre os discentes nos grupos. 


\section{RESULTADOS E ANÁLISE DOS DADOS}

De acordo com o capítulo anterior, o conhecimento e a avaliação do aprendizado foram mensurados através do instrumento utilizado, pelo método da aplicação da Taxonomia de Bloom, e foram avaliados durante a realização do procedimento e o resultado do instrumento.

A aplicação do método foi medida através da aplicação do instrumento de avaliação utilizando a técnica de Cloze. A nota atribuída teve como base o número de acerto dos quesitos presentes no instrumento, ou seja, o preenchimento correto das lacunas.

A Tabela 1 mostra o desempenho médio dos estudantes e o desvio padrão, utilizando a média da nota obtida com a aplicação do instrumento de avaliação com a técnica Cloze, nos grupos experimento e controle.

Tabela 1 - Média de nota e desvio padrão por grupo.

\begin{tabular}{c|c|c}
\hline GRUPO & MÉDIA & DESVIO PADRÃO \\
\hline Grupo Controle & 6,409 & 2,0390 \\
\hline Grupo Experimento & 7,600 & 0,6992 \\
\hline \multicolumn{2}{l}{ Fonte: Elaboração própria, 2020. }
\end{tabular}

De acordo com a Tabela 1, verifica-se que a média do grupo controle foi 6,4 , ou seja, foi inferior à média do grupo experimento 7,6 , que se levada em consideração a pontuação exigida na Faculdade para aprovação que seria 7, o grupo controle estaria abaixo.

Observando o desvio padrão é possível identificar que, o grupo controle teve mais oscilações com relação à nota individual, influenciando assim a média do grupo.

Tabela 2 - Média de idade e desvio padrão por grupo.

\begin{tabular}{c|c|c}
\hline GRUPO & IDADE & DESVIO PADRÃO \\
\hline Grupo Controle & 24,4 & 4,9258 \\
\hline Grupo Experimento & 20,7 & 2,5306 \\
\hline
\end{tabular}

Fonte: Elaboração própria, 2020.

Conforme a Tabela 2, a média de idade no grupo controle é superior à média de idade do grupo experimento, apresentando um desvio padrão que permite concluir que a oscilação de idade dentro do grupo é relativamente grande, tendo esses extremos como possível causa de alterações nas notas. $\mathrm{O}$ grupo experimento apresenta uma média de idade de 20,7 anos, com uma oscilação menor que o grupo controle. Tendo as notas como correlação, avalia-se que a idade pode ter contribuído para o desempenho dos alunos.

Para análise da distribuição dos dados do grupo controle e experimento, empregou-se o teste de normalidade Shapiro - Wilk, onde se adota que o p-valor deve ser maior ou igual a 5\%, de acordo com Miot (2016), os testes indicam a aceitação da hipótese nula de não normalidade, portanto, entende-se que a distribuição dos dados é normal.

Os dados da Tabela 3 permitem avaliar, a partir de ANOVA, através do teste $\mathrm{F}$ e do nível de significância estabelecido de $>5 \%$, que não há evidências de diferenças significativas entre os grupos controle e experimento, ou seja, infere-se que a hipótese de nulidade é verdadeira.

Tabela 3 - Análise da Variância (ANOVA).

\begin{tabular}{c|c|c|c}
\hline GRUPO & SEXO & IDADE & TIPO DE ESCOLA \\
\hline Grupo Controle & 0,752 & 3,664 & 0,233 \\
\hline Grupo Experimento & 0,788 & 0,840 & 0,856 \\
\hline \multicolumn{2}{l}{ Fonte: Elaboração própria, 2020. }
\end{tabular}


Tabela 4 - Correlação e coeficiente de Crammer-V.

\begin{tabular}{c|c|c}
\hline CORRELAÇ̃̃O & GRUPO CONTROLE & GRUPO EXPERIMENTO \\
\hline Sexo & $-0,20265$ & 0,39470 \\
\hline Idade & $-0,31608$ & $-0,20161$ \\
\hline Tipo escolar & 0,10843 & $-0,43108$ \\
\hline
\end{tabular}

Fonte: Elaboração própria, 2020.

Analisando a correlação, Tabela 4, através do coeficiente de Crammer-V, quanto ao sexo é possível verificar que no grupo controle as mulheres têm um desempenho superior ao desempenho dos homens. No grupo experimento o desempenho masculino é superior ao feminino, podendo-se enfatizar que os homens podem ser mais ativos com relação ao método de estudo Cooperativo.

A correlação idade/desempenho tanto no grupo controle quanto no grupo experimento indica que quanto maior a idade menor o desempenho, tendo o grupo controle uma porcentagem superior ao experimento, devido ao fato que no grupo controle apresentam-se mais estudantes com idades superiores aos que pertencem ao grupo experimento.

Com relação ao tipo escolar percebe-se que no grupo controle o desempenho se torna melhor se o aluno cursou seu ensino médio em escolas particulares, enquanto que no grupo experimento os melhores desempenhos foram de alunos que cursaram o ensino médio em escolas públicas, ou seja, os alunos de escola pública podem se identificar melhor ou mais facilmente a metodologias ativas.

Tendo em vista todos esses dados analisados, pode concluir-se que a média do grupo experimento foi superior e manteve uma menor oscilação nas notas que a média do grupo controle. A nota pode ter sido influenciada pelos fatores idade, sexo e tipo de escola, que, como visto anteriormente, variaram entre os grupos controle e experimento de formas diferente, enquanto no grupo controle o sexo feminino teve um desempenho superior ao masculino, no grupo experimento aconteceu o inverso, quanto a idade nos dois grupos, verificou-se que quanto menor a idade maior o desempenho. A análise do tipo de escola cursada durante o ensino médio pode sugerir que o aluno de escola particular está mais familiarizado com a metodologia tradicional de ensino, ao passo que o aluno escola pública pode estar mais apto a receber novas metodologias de ensino.

Vale ressaltar ainda que, independente do desempenho dos alunos, o método de ensino do grupo experimento proporcionou aos alunos uma maior interação, e assim aumentando a comunicação entres os colegas de classe, influenciando para que futuramente essa comunicação que é essencial para a vida profissional, tenha um ponto de partida. A menor discrepância entre as notas do método ativo de ensino mostra que a interação dos alunos contribuiu para que a aprendizagem de todos se desse de forma igualitária.

\section{CONSIDERAÇÕES FINAIS}

Esta pesquisa teve como objetivo verificar se o desempenho dos alunos é favorecido ou desfavorecido quando utilizado um método de ensino cooperativo, caracterizando a metodologia deste trabalho como um experimento, que consiste na manipulação de variáveis relacionada ao estudo, proporcionando um estudo da relação entre as causas e os efeitos, sobre o método. Ainda neste estudo é verificado se existem relações com o perfil pessoal de cada aluno, como sexo, idade e tipo de escola estudada durante o ensino médio.

Com base em todos os aspectos realizados e observados, foi possível verificar que o método cooperativo é capaz de influenciar positivamente no desempenho dos discentes, pois, 
além de promover uma maior interação entre os alunos, e estabelecer uma relação de auxílio, em relação ao método tradicional de ensino, é capaz de promover um maior aprendizado. Com isso pode-se afirmar que o método cooperativo, que tem o intuito de deixar os discentes mais à vontade e preparados para desenvolver e buscar o próprio conhecimento, foi bem aceito, e resultou em um desempenho superior ao método tradicional de ensino.

Esta pesquisa traz como contributos, que a metodologia ativa de ensino, apesar de pouco utilizada é capaz de trazer benefícios a educação de modo a desencadear no aluno um processo cognitivo, provocando a percepção e a aprendizagem, tornando-a mais prazerosa e estimulante, induzindo o aprendiz a buscar o próprio conhecimento, sem dependência de um provedor único da informação. Ainda favorece o desempenho acadêmico e a comunicação geral, que é de extrema importância na vida acadêmica e principalmente na vida profissional. A metodologia ativa de ensino é uma estratégia que não consiste em simplificar a teoria, mas auxiliar os docentes aprimorar as propostas de ensino de forma a estimular a aprendizagem pelos alunos.

Esta pesquisa foi realizada em uma única IES, utilizando apenas um conteúdo de uma disciplina de um período, todas essas características, se transformam em limitações pois, são vieses de seleção de amostra.

Sendo assim, fica-se como sugestões de trabalhos futuros, uma pesquisa com um grupo mais abrangente, em um período letivo inteiro, ou uma disciplina inteira utilizando a técnica, ou ainda realizada em Instituições de Ensino Públicas e Privadas concomitantemente a fim de se obter um comparativo.

\section{REFERÊNCIAS}

AWAYIGA, J. Y.; ONUMAH, J. M.; TSAMENYI, M. Knowledge and skills development of accounting graduates: the perceptions of graduates and employers in Ghana. Issues in Accounting Education: an International Journal, v. 19, n. 1-2, p. 139-158, 2010.

BESSA, N.; FONTAINE, A. M. Cooperar para aprender: Uma Introdução à aprendizagem cooperativa. Porto: Edições ASA, 2002.

BORMUTH, J. R. A response to "it the degrees of reading power test valid or invalid?". Journal of Reading, v. 29, n. 1, p. 42-47, out. 1985.

BORGES, L. F. M.; LEAL, E. A.; SILVA, T. D.; PEREIRA, J. M. Relação entre rendimento acadêmico e os estilos de aprendizagem: um estudo na disciplina de análise de custos. In: SemeaD, Seminário de Administração, XX, 2017, São Paulo. Anais [...]. São Paulo: USP, 2017.

CERVO, A. L.; BERVIAN, P. A.; SILVA, R. Metodologia Científica. 6. ed. São Paulo: Pearson Prentice Hall, 2007.

CONCEIÇÃO, M.G.; CASTRO, M. R.; GUIMARÃES, I. P.; AZEVEDO, T.C. Estilos de Aprendizagem sob a Ótica do Inventários de David Kolb: um Estudo de Caso com os Alunos de Graduação do Curso de Ciências Contábeis da UFBA. Revista de Contabilidade da

Bahia, v. 1, n.1, p. 61-72, 2013. 
CORBUCCI, P. R. Desafios da educação superior e desenvolvimento no Brasil. Brasília: IPEA, Instituto de Pesquisa Econômica Aplicada, 2007.

CORDEIRO, R. A.; DA SILVA, A. B. Os estilos de aprendizagem influenciam o desempenho acadêmico dos estudantes de finanças?. Revista de Administração UFSM, Santa Maria, v. 5, n. 2, p. 243-261, mai./ago. 2012.

CUNHA, F.; UVA, M. A aprendizagem cooperativa: perspectiva de docentes e crianças. Revista Interações, v.12, n. 41, p. 133-159, 2016.

DALFOVO, M. S. et al. Análise da relação dos estilos de aprendizagem na percepção do método de ensino. Revista de Administração e Negócios da Amazônia, v. 9, n. 3, mai./ago. 2017.

FERRAZ, A. P. C. M.; BELHOT, R. V. Taxonomia de Bloom: revisão teórica e apresentação das adequações do instrumento para definição de objetivos instrucionais. Revista Gestão \& Produção, São Carlos, v. 17, n. 2, p. 421-431, 2010.

FILATRO, A. Produção de Conteúdos Educacionais. São Paulo: Saraiva, 2015.

FLEMING, Neil D.; MILLS, Colleen. Not another inventory, rather a catalyst for reflection. To improve the academy, v. 11, n. 1, p. 137-155, 1992.

GALHARDI, A. C.; AZEVEDO, M. M. Avaliações de aprendizagem: o uso da taxonomia de Bloom. In: Workshop de Pós-Graduação e Pesquisa do Centro Paula Souza, VIII, 2013., São Paulo. Anais [...]. São Paulo, Centro Paula Souza, 2013.

GIL, A. C. Métodos e técnicas de pesquisa social. 6. Ed. São Paulo: Atlas, 2008.

IFAC. Handbook of International Education Pronouncements. New York: International Accounting Education Standards Board, 2012.

KRATHWOHL, D. R. A revision of bloom's taxonomy: an overview. Theory into Practice, n. 41, v. 4., p. 212-218, 2002.

LIMA FILHO, R. N.; JESUS, D. A. N. Nível de Aprendizagem do Estudante de Contabilidade: um Modelo de Diagnóstico a partir da Taxonomia Revisada de Bloom. Revista de Contabilidade da UFBA, v. 7, p. 38-58, 2013.

LOPES, J.; SILVA, H. S. A Aprendizagem Cooperativa na Sala de Aula: Um Guia Prático Para o Professor. Lisboa: Lidel. 2009.

MIOT, H. A. Avaliação da normalidade dos dados em estudos clínicos e experimentais. Jornal Vascular Brasileiro., v. 16, n. 2, p. 88-91, abr./jun. 2017.

MIRANDA, R. A. M.; MIRANDA, C. S.; COSTA, G. F. M. Estratégias de Ensino e Estilos de Aprendizagem: Um Experimento no Processo Ensino Aprendizagem na Disciplina de 
Contabilidade Introdutória. In: Encontro De Ensino e Pesquisa em Administração e Contabilidade, III, 2011, João Pessoa. Anais [...]. São Paulo, ANPAD, 2011.

MUNHOZ, A. M. H. Uma análise multidimensional da relação entre inteligência e desempenho acadêmico em universitários ingressantes. Tese (Doutorado) - Universidade Estadual de Campinas, Faculdade de Educação, Campinas, 2004.

PEREIRA, I.V.; SILVA, C. A. T. Aprendizagem cooperativa como estratégia de ensino para a contabilidade: habilidades intelectuais da taxonomia do domínio cognitivo. Revista Ambiente Contábil, v. 10, n. 1, jan./jun. 2018.

PINHEIRO, F. M. G.; DIAS FILHO, J. M.; LIMA FILHO, R. N.; LOPES, L. M. S. O Perfil do Contador e os Níveis de Habilidades Cognitivas nos Exames ENADE e Suficiência do CFC: Uma análise sob a perspectiva da Taxonomia de Bloom. Contextus, v. 11, p. 50-65, 2013.

PRODANOV, C. C.; FREITAS, E. C. Metodologia do trabalho científico: métodos e técnicas da pesquisa e do trabalho acadêmico. 2. ed. Novo Hamburgo: Feevale, 2013.

REBELE, J. E. An examination of accounting students perceptions of the importance of communication skills in public accounting. Issues in Accounting Education, n. 3, p. 41-50, 1985.

REIS, L. G.; PATON, C.; NOGUEIRA, D. R. Estilos de aprendizagem: uma análise dos alunos do curso de Ciências Contábeis pelo método Kolb. Revista Enfoque: Reflexão Contábil, v. 31, n. 1, p. 53-66. 2012.

SANTOS, J. F. S. Avaliação no ensino a distância. Revista Ibero-americana de Educação, v. 38, n. 4, p. 1-9, 10 abr. 2006.

SHAFTEL, J.; SHAFTEL, T. L. Educational Assessment and the AACSB. Issues in Accounting Education, v. 22, n. 2, p. 215-232, 2007.

SILVA, A. B.; LIMA, T. B.; SONAGLIO, A. L. B.; GODOI, C. K. Dimensões de um sistema de aprendizagem em ação para o ensino de administração. Revista Administração: Ensino e Pesquisa, v. 13, n. 1, p. 9-41, 2012..

VEIGA, I. P. A. Técnicas de ensino: novos tempos, novas configurações. Campinas: Papirus Editora, 2006.

\section{APENDICE A - MATERIAL DE ENSINO GRUPO EXPERIMENTAL}

\section{APURAÇÃO DO RESULTADO DO EXERCÍCIO}

\section{CONTAS DE RESULTADOS}

Assim como as contas patrimoniais são consideradas permanentes, pois enquanto houver saldo as mesmas existirão, as contas de resultados são consideradas transitórias, pois ao 
fim de cada exercício social, serão encerradas, ou seja, terão os seus saldos serão zerados, para que se possa apurar o RESULTADO DO EXERCÍCIO (lucro ou prejuízo).

Para que isso ocorra, é necessário que se crie uma conta transitória chamada Apuração do Resultado de Exercício (ARE).

Exemplos de conta de resultado:

- Contas de Receitas;

- Contas de Despesas.

\section{APURAÇÃO DO RESULTADO}

A cada exercício social (normalmente, um ano) a empresa deve apurar o resultado dos seus negócios. Para saber se obteve lucro ou prejuízo, a contabilidade confronta a receita (vendas) com as despesas. Se a receita foi maior que a despesa, a empresa teve lucro. Se a receita foi menor que a despesa, teve prejuízo. A apuração de resultado é realizada de forma destacada na Demonstração do Resultado do Exercício. É apresentado um resumo ordenado das despesas e receitas do período, facilitando a tomada de decisão. De maneira geral, através da apuração do resultado pode-se verificar se o maior objetivo da empresa foi atingido, ou seja, se os benefícios obtidos foram maiores que os sacrifícios realizados.

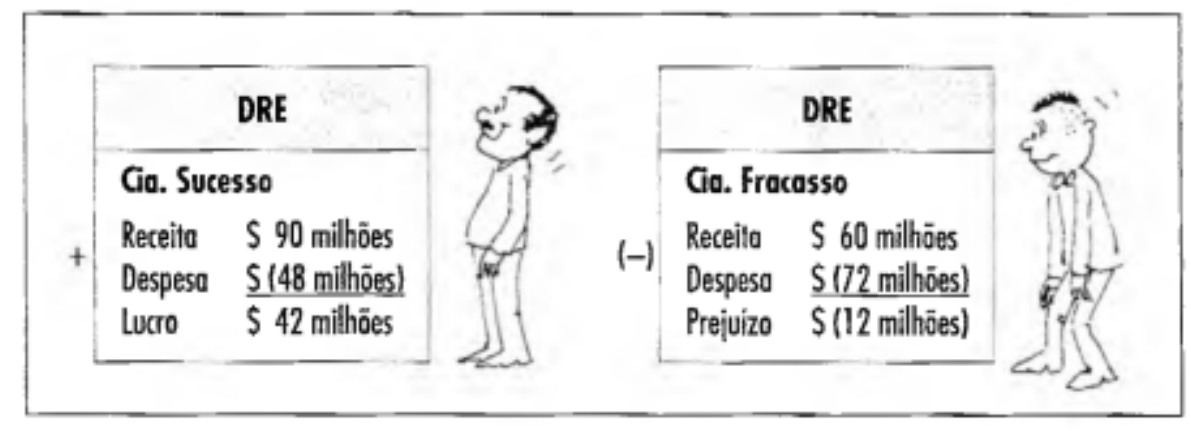

\section{CONCEITO DE RECEITA E DESPESA}

A receita corresponde, em geral, a vendas de mercadorias ou prestações de serviços. Ela é refletida no balanço através da entrada de dinheiro no Caixa (Receita a Vista) ou entrada em forma de direitos a receber (Receita a Prazo) - Duplicatas a Receber.

A receita sempre aumenta o Ativo embora nem todo aumento de Ativo signifique Receita (empréstimos bancários, financiamentos etc. aumentam o Caixa-Ativo da empresa, mas não são receitas).

A Despesa é todo sacrifício, todo esforço da empresa para obter Receita (Todo consumo de bens ou serviços com o objetivo de obter Receita é um sacrifício um esforço para a empresa). Ela é refletida no balanço através de uma redução do Caixa (quando é pago no ato - a vista) ou mediante um aumento de uma dívida - Passivo (quando a despesa é contraída no presente para ser paga no futuro - a prazo). A despesa pode, ainda, originar-se de outras reduções de Ativo (além do Caixa), como é o caso de desgastes de máquinas (depreciação) e outros.

\section{ENCERRAMENTO DAS CONTAS DE RESULTADO}

Conforme exigência legal, pelo menos uma vez por ano as empresas estão obrigadas a encerrar todas as contas de resultado. Esse encerramento ocorre no momento do confronto das despesas com as receitas para apurar o resultado. Com o encerramento das contas de receita e despesa, todas as contas de 
resultado ficam com saldo zero para o início do próximo período contábil. Assim começa-se a acumular receita e despesa do próximo período até o final do período em que novamente serão encerradas as contas de resultado, apurando-se o lucro ou prejuízo, e assim sucessivamente.

\section{LANÇAMENTOS DE ENCERRAMENTO}

1. Abre-se uma conta transitória com o título de "Apuração do Resultado do Exercício (ARE)", em que se realiza o confronto receita x despesa;

2. Transfere-se o saldo das contas de receitas e despesas para a conta de resultados (ARE). Note-se que nessa transferência encerram-se as contas de Receita e Despesa.

Exemplo de encerramento

Considerando as seguintes contas de resultado da Companhia Magnelândia:

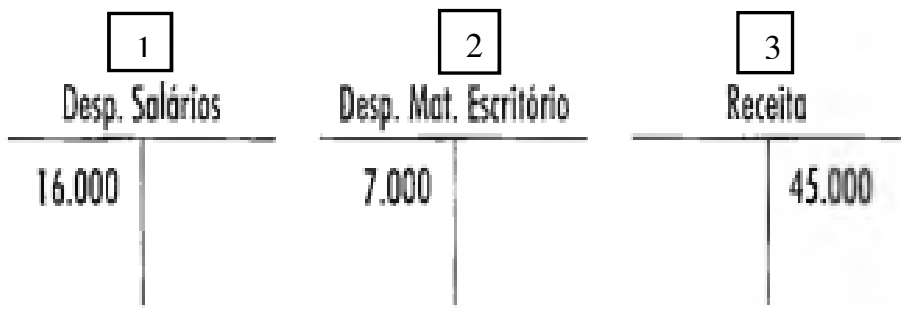

Encerram-se agora essas contas, igualando-se o saldo a zero (assim, para o ano seguinte, inicia-se a acumulação de despesa e receita novamente). Para encerrar as contas de despesas, basta creditar idêntico valor (a contrapartida será débito de ARE - Apuração de Resultado do Exercício). Para encerrar a conta receita, basta debitar valor idêntico - $\$ 45.000$ (a contrapartida será crédito de ARE).

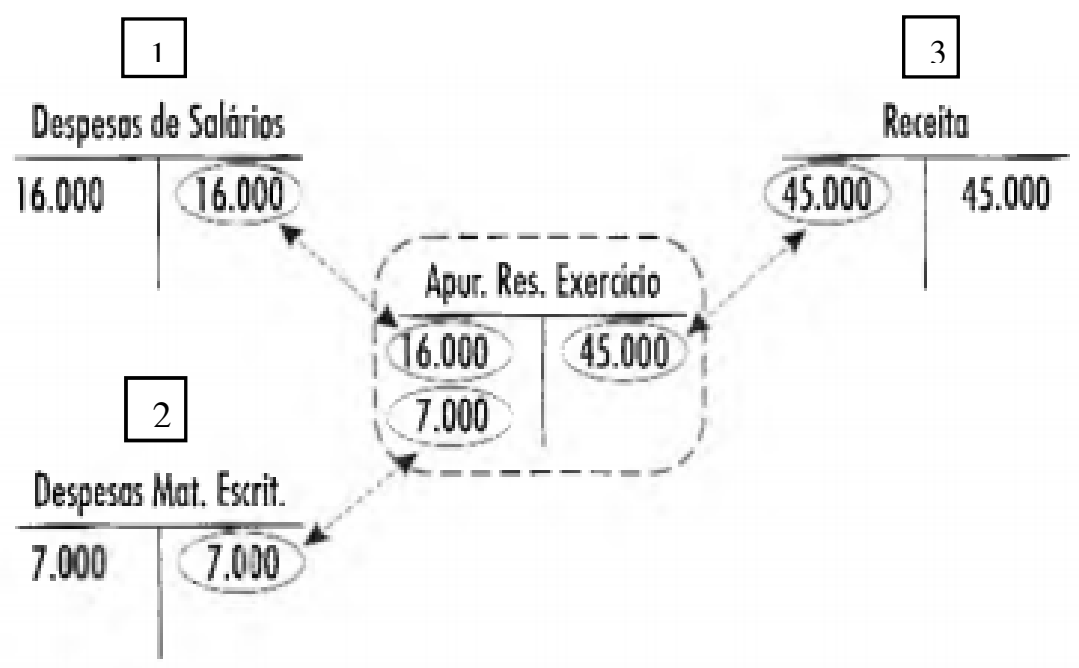

Se o total da receita for maior que o total de despesa, haverá lucro; se a receita for menor que a despesa, haverá prejuízo.

No exemplo apresentado, têm-se \$45.000 de receita contra \$23.000 de despesa; portanto, houve um lucro de $\$ 22.000$ (\$ 45.000 - \$23.000). 


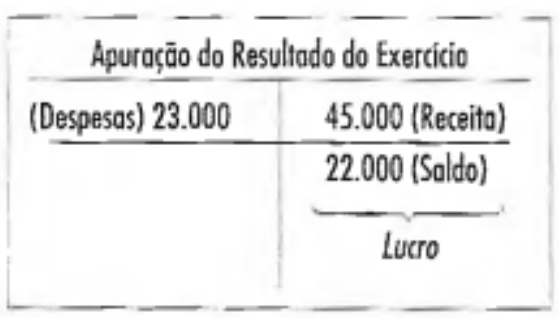

O saldo maior no lado da receita indica contabilmente lucro.

O lucro que é apurado pela Contabilidade é canalizado para diversas finalidades: a principal é a distribuição em dinheiro para os donos do negócio. O lucro năo distribuído nem destinado para fins específicos é que chamamos de Lucro Retido.

\section{CONTABILIZAÇÃO DO RESULTADO}

Todo lucro acresce o Patrimônio Líquido. O lucro é a remuneração aos proprietários da empresa pelo capital investido. Os recursos dos proprietários aplicados na empresa são evidenciados no Patrimônio Líquido (capital próprio). Dessa forma, a participação dos proprietários na empresa será maior com o acúmulo do lucro no PL.

Por conseguinte, partindo-se da hipótese de que não há, por enquanto, distribuição do lucro em dinheiro (dividendos) aos proprietários, o PL será acrescido de $\$ 22.000$. A conta que receberá os \$22.000 é Lucros Acumulados. Aumentando-se o PL, tem-se um crédito:

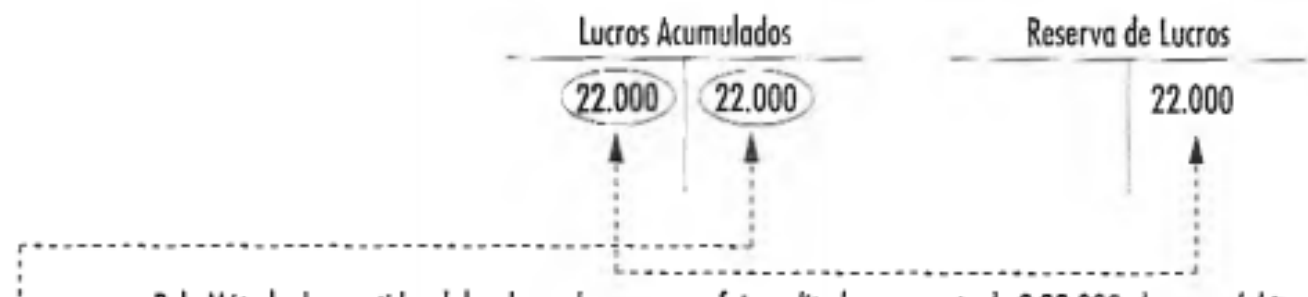

Pelo Método das partidas dobrados, sabe-se que se foi creditoda uma conta de $\$ 22.000$, deve-se debilar outra(s) conta(s) cujo total seja \$22.000. A conta a ser debitada será a de "Resultados" (ARE), pois, como foi dito, é uma conta transitória, que serve única e exclusivamente para apuraçôo do resultado do exercicio. Com esse lonçamento a débito, encerro-se a conta Resultados (ARE), uma vez que já cumpriu sua missóa: confrontar receita com despesa e apurar o resultado (Lucro ou Prejuizo).

Apuraçōo do Res. do Exercício

\section{$22.000) 22.000$}

Se houvesse prejuízo, o saldo da conta ARE seria devedor; portanto, o lançamento seria o contrário: crédito da conta ARE e débito de Prejuízos Acumulados. \$18.600.

Admita-se, agora, que a Companhia Desilusão apresente um prejuízo de 


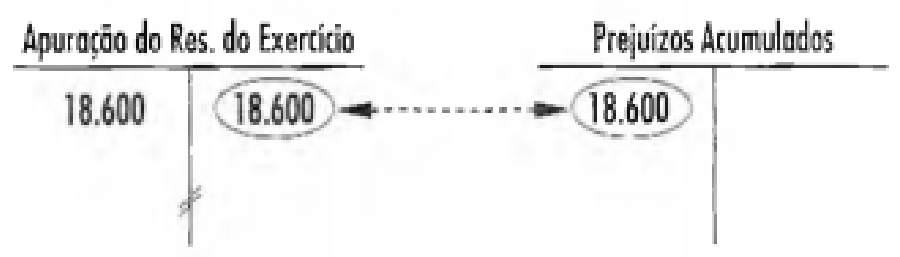

A conta Prejuízos Acumulados faz parte do Patrimônio Líquido com o sinal negativo (18.600), ou seja, reduz os investimentos dos proprietários.

Exemplo Resolvido

Suponha-se que, ao final de um exercício social, uma empresa tenha apurado os seguintes saldos das contas de Resultado:

\begin{tabular}{|l|c|}
\hline & $\mathrm{R} \$$ \\
\hline Vendas & 98.000 \\
\hline Custo de mercadoria vendida & 42.000 \\
\hline Salários & 27.000 \\
\hline Despesas Gerais & 9.000 \\
\hline
\end{tabular}

Transpondo para os Razonetes:

$\frac{\text { Vendas }}{198.000} \quad \frac{\text { Custo de merc. Vendas }}{42.0001}-\frac{\text { Salários }}{27.0001} \quad \frac{\text { Despesas Gerais }}{9.0001}$

Para encerrar essas contas, deve-se creditar as despesas e debitar as receitas em contrapartida com a conta transitória ARE:

$\frac{\text { Vendas }}{98.000 \mid 98.000} \quad \frac{\text { Custo de merc. Vendas }}{42.000 \mid 42.000} \quad \frac{\text { Salários }}{27.000 \mid 27.000} \quad \frac{\text { Despesas Gerais }}{9.000 \mid 9.000}$

\begin{tabular}{r|l}
\multicolumn{2}{c}{$\mathbf{A R E}$} \\
\hline 42.000 & 98.000 \\
27.000 & \\
9.000 & \\
\hline & $\mathbf{2 0 . 0 0 0}$
\end{tabular}

\section{PRATICANDO:}

1) Considere as contas de Resultado a seguir e apure o resultado do exercício.

Receita Bruta: R\$35.000

Despesas administrativas: $\mathrm{R} \$ 5.000$

Despesas operacionais: $\mathrm{R} \$ 4.000$

Despesas com vendas: $\mathrm{R} \$ 6.000$

2) A tabela a seguir apresenta as contas de resultado de uma empresa comercial e os respectivos saldos. 


\begin{tabular}{|l|c|}
\hline Custo de mercadorias e serviços & 38.000 \\
\hline Depreciação e amortização & 2.500 \\
\hline Despesa financeira & 2.700 \\
\hline Despesas com vendas & 18.000 \\
\hline Despesas gerais e administrativas & 3.100 \\
\hline Outras despesas operacionais & 4.000 \\
\hline Receita bruta & 85.000 \\
\hline
\end{tabular}

A apuração do resultado mostra um prejuízo líquido de $\mathrm{R} \$ 1.200,00$.

a) Certo.

b) Errado.

\title{
Referências:
}

MARION, J. C. Contabilidade Básica. São Paulo: Atlas, 1998.

FERRARI, E. L. Contabilidade Geral. Niteroí - RJ: Impetus, 2012.

\section{APÊNDICE B - INSTRUMENTO DE AVALIAÇÃO}

\section{PERFIL}

\author{
Pesquisa para TCC - Ciências Contábeis
}

Sexo:

$\square$ Feminino

$\square$ Masculino

Idade:

Tipo de escola que cursou o ensino Médio:

$\square$ Pública

$\square$ Particular

$\square$ Ambas

\section{AVALIAÇÃO DO APRENDIZADO}

1. Para saber se houve Lucro ou prejuízo a contabilidade confronta as contas de e

2. Para o aumento do saldo deve-se debitar uma na ARE.

3. A contrapartida na ARE de uma despesa será

4. A contrapartida na ARE de uma receita será

5. Ao fim de cada exercício social, as contas de serão encerradas.

6. Para o lançamento de encerramento deve-se primeiramente abrir uma conta com o título de

7. Para encerrar uma conta de despesa, deve-se o mesmo valor.

8. Para encerrar as contas de Receita deve-se o mesmo valor.

9. O valor da Receita sendo superior ao da Despesa, o resultado será

10. O valor da Despesa sendo superior ao da Receita, o resultado será 